Article

\title{
Polyamide Fiber Reinforced Shotcrete for Tunnel Application
}

\author{
Joong Kyu Jeon ${ }^{1}$, WooSeok Kim ${ }^{2, *}$, Gyu Yong Kim ${ }^{3}$ and Chan Ki Jeon ${ }^{4}$ \\ 1 R \& BD Center, Kolon Global Corp., Yongin, Gyunggi 17023, Korea; jkjeon31@kolon.com \\ 2 Department of Civil Engineering, Chungnam National University, Daejeon 34134, Korea \\ 3 Department of Architectural Engineering, Chungnam National University, Daejeon 34134, Korea; \\ gyuyongkim@cnu.ac.kr \\ 4 Department of Urban Construction Engineering, Incheon National University, Incheon 22012, Korea; \\ johnland@incheon.ac.kr \\ * Correspondence: wooseok@cnu.ac.kr; Tel.: +82-42-821-6584; Fax: +82-42-825-0318
}

Academic Editor: Luciano Feo

Received: 3 February 2016; Accepted: 1 March 2016; Published: 5 March 2016

\begin{abstract}
This study intends to establish the mechanical properties of polyamide fiber reinforced shotcrete (PAFRS) in terms of compressive and flexural strengths, in accordance with ASTM C1609/C1609M-12. The mechanical properties identified the influence of polyamide fiber content on the PAFRS strength. This study evaluated the toughness of PAFRS and proposed additional toughness level criteria to better represent organic fiber performance. In addition, the fiber rebounding rate and PAFRS performance in tunneling application were evaluated based on a tunnel application in Korea. PAFRS with $0.6 \% \sim 0.8 \%$ volume content in tunneling shotcrete could significantly improve flexural ductility, toughness, and ultimate load capacity. Fiber rebounding tests exhibited a low rebounding rate $(8.5 \%)$ and low fiber drop $(63.5 \%)$. Therefore, PAFRS applied to a tunnel exhibited stability and constructability.
\end{abstract}

Keywords: fiber; macro; polyamide; shotcrete; tunnel

\section{Introduction}

Concrete and cementitious materials are vulnerable to tension developing in individual components and structures. Reinforcing materials such as steel fibers [1-6] are commonly used in concrete structures to control cracks [7-12]. The application of steel fiber reinforced shotcrete (SFRS) in tunneling construction has been part of tunneling practice since the 1970s, especially in Europe and the United States [13-16]. SFRS is characterized by ductile behavior, namely better post-cracking strength and energy absorption, where the latter is referred to as the "toughness" of a material. More specifically, toughness is the amount of energy that is absorbed before and after fracture [16].

Polyamide fiber reinforced shotcrete (PAFRS) was developed to improve mechanical properties and workability. The detailed manufacturing process has been described in other documents $[17,18]$. A comparison of $0.47 \mathrm{~m}$ diameter and $30 \mathrm{~mm}$ long polyamide (PA) fiber to $1.0 \mathrm{~mm} \times 0.5 \mathrm{~mm}$ rectangular and $42 \mathrm{~mm}$ long polypropylene (PP) fiber [19] shows that $650 \mathrm{MPa}$ tensile strength of PA fiber is higher than $550 \mathrm{MPa}$ of PP fiber, though PA fiber (3 GPa) has less elastic modulus than PP fiber (8.2 GPa). Note also that a higher density of PA fiber $\left(1.14 \mathrm{~g} / \mathrm{cm}^{3}\right)$ compared to PP fiber $\left(0.9-0.92 \mathrm{~g} / \mathrm{cm}^{3}\right)$ is advantageous because higher density of PA fiber prevents the fiber from floating in the cement matrix.

Compared to steel fibers, PA fiber has lower weight density, which prevents the fiber from sinking down in the cement matrix and improves the durability without corrosion. Steel fibers may sometimes induce a mixing problem that prevents a uniform distribution of fibers in concrete [20]. 
The improved mechanical and mixing properties and adhesion characteristics of PA fiber lead to improved workability and less rebounding during spouting of shotcrete.

The objective of this study is to establish PAFRS mechanical properties in terms of compressive and flexural strengths, in accordance with ASTM C1609/C1609M-12 [21]. The mechanical properties reveal the influence of PA fiber content on the PAFRS strength. This study evaluated the toughness of PAFRS using the Morgan level [14] and proposed additional toughness level criteria to better represent organic fiber performance. In addition, based on PAFRS application in Korea, the rebounding rate and performance in a tunneling application were evaluated. PA fibers in tunneling shotcrete significantly improved flexural ductility, toughness, and ultimate load capacity.

\section{Characterization of PAFRS Flexural Strength}

Flexural strength of PAFRSs can be tested in accordance with ASTM C1609/C1609M-12 [21]. As in Figure 1, this study identified two peak loads: (1) the first-peak load $\left(P_{1}\right)$ on the load-deflection curve, which was caused by crack initiation of the specimen; and (2) the second-peak load $\left(P_{2}\right)$ on the load-deflection curve when the PA fibers reached the ultimate strength. Corresponding strengths and deflections are denoted as $f_{1}$ and $\delta_{1}$ for $P_{1}$ and $f_{2}$ and $\delta_{2}$ for $P_{2}$, respectively. Residual loads $\left(P_{600}^{D}\right.$ and $\left.P_{150}^{D}\right)$ and strength $\left(f_{600}^{D}\right.$ and $\left.f_{150}^{D}\right)$ at a net deflection of $L / 600$ and $L / 150(L=$ clear span) were measured for a beam with a depth of $d\left(=100 \mathrm{~mm}\right.$ in Figure 2a). Toughness $\left(T_{150}^{D}\right)$ and equivalent flexural strength ratio $\left(R_{T, 150}^{D}\right)$ at a net deflection of $L / 150(=300 \mathrm{~mm}$ in Figure 2a) were also identified. Flexural strength of $f_{1}$ and $f_{2}$, equivalent bending strength of $f_{e}$ and equivalent flexural strength ratio of $R_{T, 150}^{D}$ were computed as follows:

$$
\begin{gathered}
f_{i}=\frac{P_{i} L}{b d^{2}} \\
f_{e}=\frac{A_{b} L}{\delta_{150} b d^{2}} \\
R_{T, 150}^{D}=\frac{f_{i}}{f_{e}} \times 100(\%)=\frac{150 \cdot T_{150}^{D}}{f_{1} \cdot b \cdot d^{2}} \times 100(\%)
\end{gathered}
$$

where $P_{i}=i^{\text {th }}$ peak load at $\delta_{i} ; L=$ clear span length $(=300 \mathrm{~mm}) ; b$ and $d=$ beam cross-section width and depth at the fracture surface, respectively; $A_{b}=$ area under the load-deflection curves up to $\delta_{150}$ $(\mathrm{N} \cdot \mathrm{mm})$; and $\delta_{150}=$ deflection of $L / 150(=2.0 \mathrm{~mm})$.

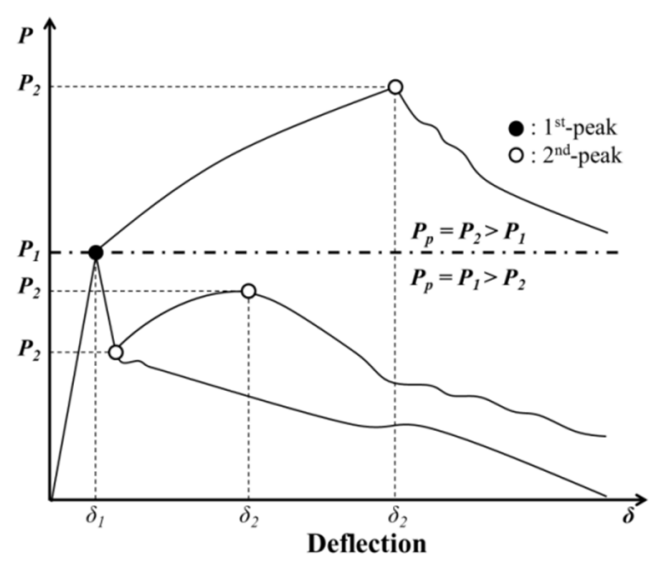

Figure 1. Typical load-deflection responses of FRC. 


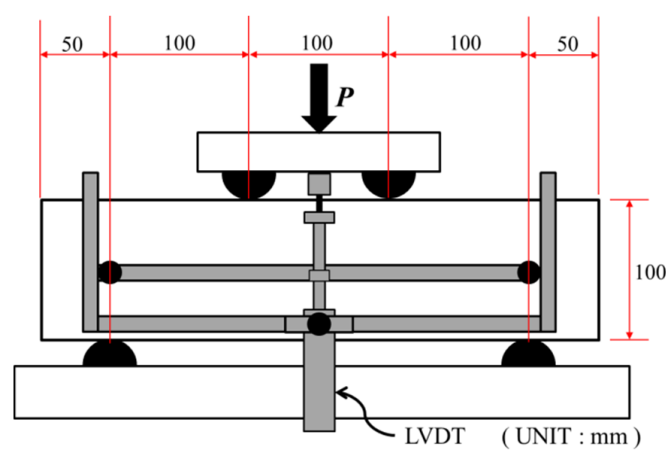

(a)

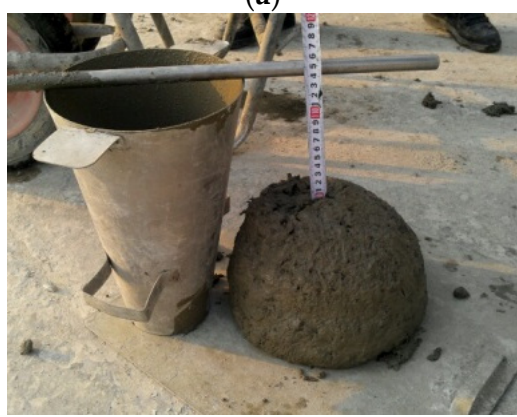

(c)

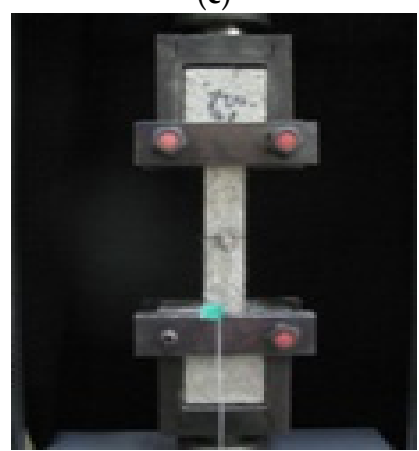

(e)

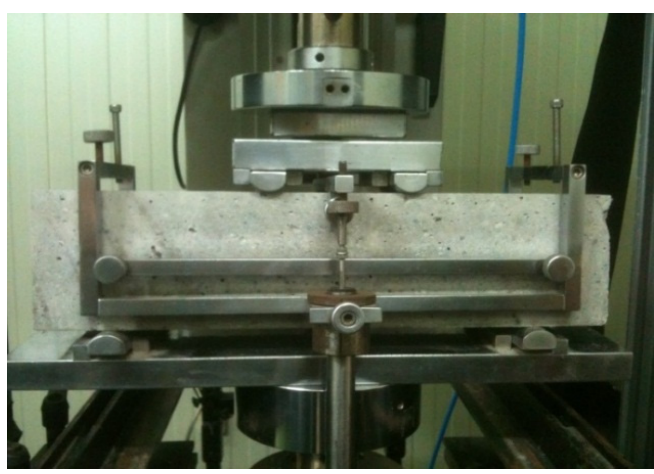

(b)

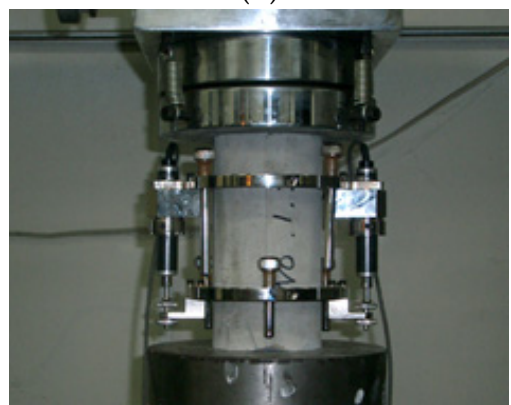

(d)

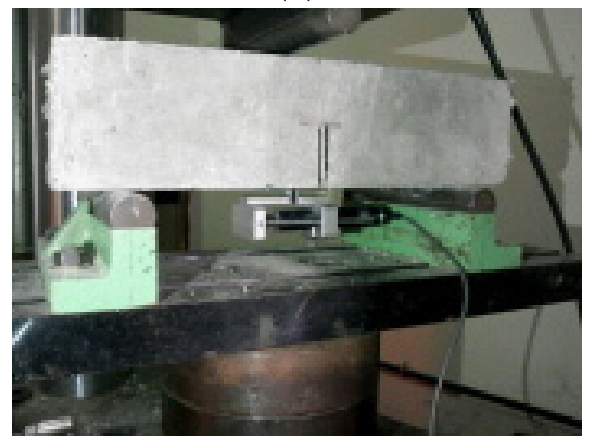

$(\mathbf{f})$

Figure 2. (a) Specimen geometry for bending test; (b) test set-up picture of bending test; (c) slump test; (d) compressive test; (e) direct tensile test; (f) fracture test.

Based on the deflection $\left(\delta_{1}\right)$ at the first-peak load, three additional points were investigated at $3 \delta_{1}, 5.5 \delta_{1}$, and $10.5 \delta_{1}$ as per ASTM C1018-97 [22]. The current ASTM standard [21] specifies $\delta_{1}, \delta_{p}$ (deflection at the peak load regardless of the first-peak or second-peak), L/600 and L/150. However, PAFRS occasionally exhibits a larger second peak than the first peak depending on the PA fiber volume content. Thus, this study clearly stipulated pre-(1st peak) and post(2nd peak)-cracking strengths. Also, PAFRS displays yielding after cracking before the PA fiber reaches its ultimate strength, similar to hyper-elastic materials. Thus, additional points at $3 \delta_{1}, 5.5 \delta_{1}$, and $10.5 \delta_{1}$ were used in this study.

\section{PA Fiber Volume Content Influence on PAFRS Mechanical Properties}

The PAFRS specimens were prepared with varying PA fiber content ratios from $0.0 \%$ to $1.5 \%$. Detailed shotcrete mix design of water to cement ratio (W/C), sand to aggregate ratio (S/a), water $(\mathrm{W})$, cement (C), fly ash (FA), sand (S), gravel (G), and water-reducing admixture (AD) is presented in Table 1. The PAFRS was tested for slump, bending strength, direct tensile strength, and fracture energy, as shown in Figure 2. A bending test was performed in accordance with ASTM C1609/C1609M-12 [21]. A rectangular beam was saw-cut to dimensions of $100 \mathrm{~mm} \times 100 \mathrm{~mm} \times 400 \mathrm{~mm}$. To carry out compressive tests, a $\varphi 100 \mathrm{~mm} \times 200 \mathrm{~mm}$ cylindrical specimen was used. A direct tensile test was 
conducted used a dog-bone shaped specimen. For a fracture energy test, a rectangular specimen of $100 \mathrm{~mm} \times 100 \mathrm{~mm} \times 400 \mathrm{~mm}$, which is the same as to the specimen employed in the bending strength test, was used and the test procedure followed RILEM TCS [23]. The obtained test results with respect to varying PA fiber contents are tabulated in Table 2.

Table 1. Shotcrete mix design.

\begin{tabular}{cccccccccc}
\hline \multirow{2}{*}{ Types } & \multirow{2}{*}{$\begin{array}{c}\text { Fiber Content } \\
\text { (vol \%) }\end{array}$} & W/C (\%) & S/a (\%) & \multicolumn{5}{c}{ Unit Weight $\left(\mathbf{k g} / \mathbf{m}^{\mathbf{3}}\right)$} & \multirow{2}{*}{ AD (B * \%) } \\
\cline { 5 - 7 } & & & & W & C & FA & S & G & \\
\hline Plain & - & 40 & 44.4 & 163 & 326 & 82 & 749 & 938 & 0.3 \\
PA-0.50 & 0.50 & 40 & 44.4 & 163 & 326 & 82 & 749 & 938 & 1.0 \\
PA-0.75 & 0.75 & 40 & 55.0 & 180 & 360 & 90 & 904 & 740 & 1.0 \\
PA-1.00 & 1.00 & 40 & 55.0 & 180 & 360 & 90 & 904 & 740 & 1.2 \\
PA-1.25 & 1.25 & 40 & 55.0 & 188 & 376 & 94 & 883 & 722 & 1.6 \\
PA-1.50 & 1.50 & 40 & 55.0 & 188 & 418 & 104 & 857 & 701 & 1.7 \\
\hline
\end{tabular}

${ }^{*}$ weight percentage to binder.

Table 2. PAFRS mechanical properties.

\begin{tabular}{cccccccc}
\hline Specimen & $\begin{array}{c}\text { Slump } \\
(\mathbf{m m})\end{array}$ & $\begin{array}{c}\text { Compressive } \\
\text { Strength } \\
\mathbf{( M P a )}\end{array}$ & $\begin{array}{c}\text { Elastic } \\
\text { Modulus } \\
\mathbf{( M P a )}\end{array}$ & $\begin{array}{c}\text { Direct } \\
\text { Tensile } \\
\text { Test (MPa) }\end{array}$ & $\begin{array}{c}\text { Bending } \\
\text { Strength } \\
\mathbf{( M P a )}\end{array}$ & $\begin{array}{c}\text { Equivalent } \\
\text { Bending Strength } \\
\mathbf{( M P a )}\end{array}$ & $\begin{array}{c}\text { Fracture } \\
\text { Energy } \\
\left(\mathbf{N} \cdot \mathbf{m} / \mathbf{m}^{\mathbf{2}}\right)\end{array}$ \\
\hline Plain & 150 & 44.94 & 30,119 & - & 6.42 & - & 908.45 \\
PA-0.50 & 155 & 42.86 & 28,930 & 2.00 & 6.38 & 4.22 & 4010.66 \\
PA-0.75 & 140 & 43.69 & 25,784 & 1.60 & 7.76 & 5.94 & 5674.95 \\
PA-1.00 & 130 & 47.44 & 28,783 & 2.30 & 7.13 & 7.05 & 7286.54 \\
PA-1.25 & 140 & 49.82 & 23,194 & 2.48 & 8.64 & 6.57 & 8750.07 \\
PA-1.50 & 130 & 50.35 & 23,357 & 2.63 & 8.85 & 7.22 & $10,132.19$ \\
\hline
\end{tabular}

\subsection{Compressive Strength and Elastic Modulus}

As presented in Figure 3, compressive strength tests were performed for PAFRS specimens with varying PA fiber content from $0.0 \%$ to $1.5 \%$. It was clearly observed that the slope or elastic modulus of PAFRS decreased as the PA fiber content increased. Obtained maximum compressive strengths with respect to PA fiber content from $0.0 \%$ to $1.5 \%$ are shown in Table 2 . However, the maximum compressive strengths of PA-0.5 and PA-0.75 (42.86 and $43.69 \mathrm{MPa})$ were less than that of Plain (44.94 MPa), but those of PA-1.00, PA-1.25 and PA-1.50 (47.44, 49.82 and $50.35 \mathrm{MPa})$ were larger than that of Plain. This phenomenon is commonly encountered in fiber-reinforced concrete.

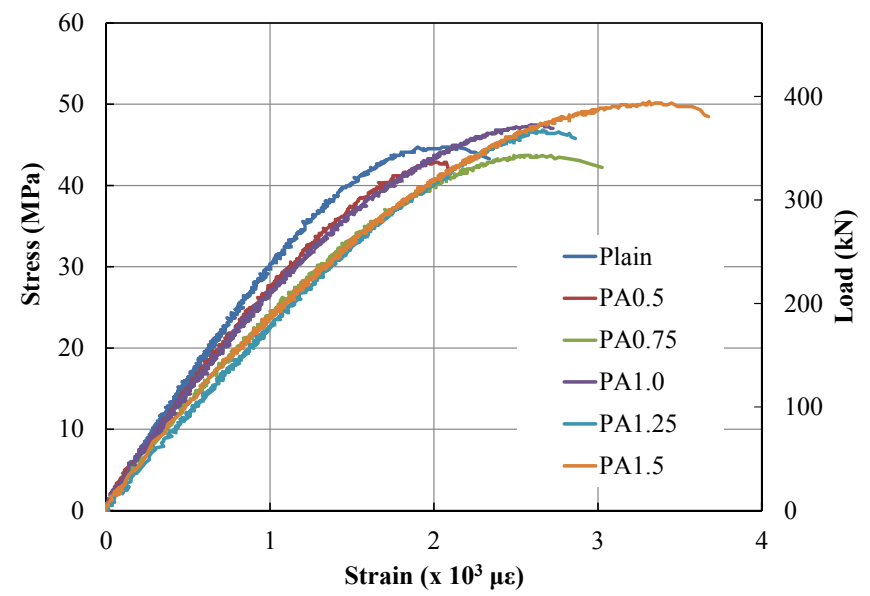

Figure 3. Compressive stress-strain curves of PAFRSs with varying PA contents. 
The elastic moduli of the PAFRS specimens slightly decreased compared to those of the plain specimen. The elastic modulus of the plain shotcrete mix was larger than those of PAFRSs. The elastic moduli of PAFRSs were not proportional to the PA fiber content. The order of magnitude of the PAFRS elastic modulus was $0.5 \%>1.0 \%>0.75 \%>1.5 \%>1.25 \%$ in terms of PA fiber content.

\subsection{Direct Tensile Strength Test}

Direct tensile strength test results are presented in Figure 4. It was observed that the shotcrete toughness was significantly improved by inclusion of PA fibers. The tensile strength tended to linearly increase as the PA fiber content increased, except for the PA- 0.75 specimen. The maximum tensile strength is shown in Table 2. In Figure 4, the 1st peak tensile strengths were 2.00, 1.60, 2.48, 2.30, and $2.08 \mathrm{MPa}$ for PA-0.5, 0.75, 1.25, 1.0, and 1.5. The 2nd peak tensile strengths were 0.82, 1.16, $2.26,0.73$, and 2.63 MPa for PA-0.5, 0.75, 1.25, 1.0, and 1.5. All specimens exhibited larger first peak tensile strengths than the second peak strengths except for the PA-1.5 specimen. The PA-1.5 specimen exhibited a larger second peak tensile strength than the first peak tensile strength. It was expected that the PA fiber content generally increased the second peak strength.

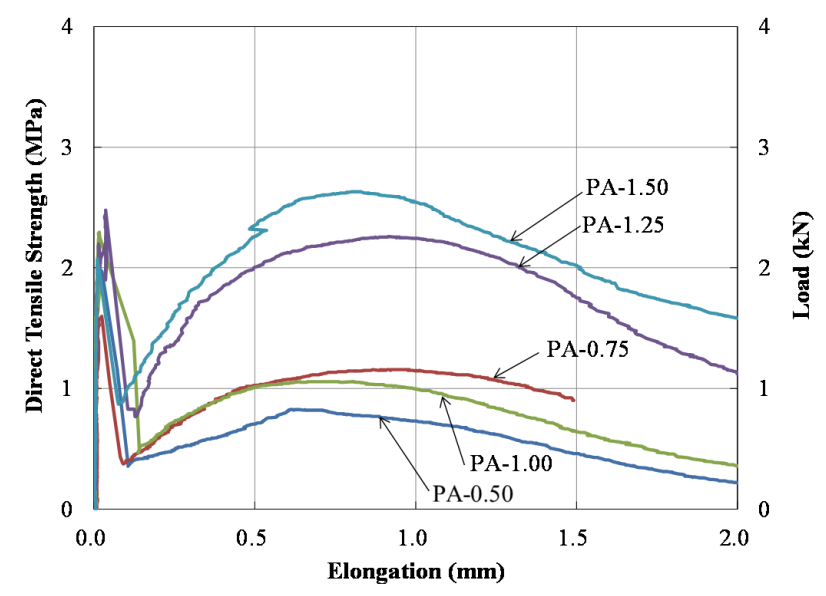

Figure 4. Direct tensile test results.

\subsection{Flexural Bending Test Results}

Flexural bending test results are presented in Figure 5. Similar to the direct tensile test results, the flexural bending strengths were significantly improved by PA fibers. As aforementioned, the PAFRS exhibited two distinct peaks: (1) the first peak was induced by the initiation of the crack; and (2) the second peak was reached as the fiber reached its ultimate strength.

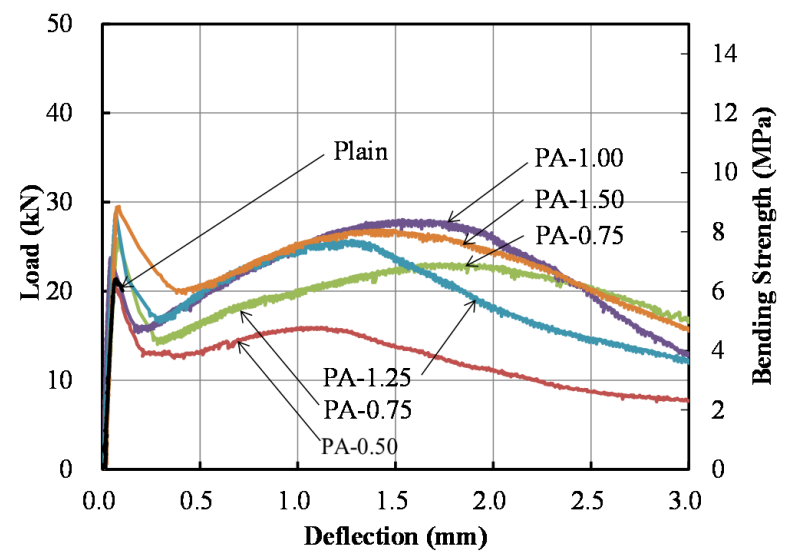

Figure 5. Load-deflection curves of flexural bending tests. 
Detailed flexural responses at various points are presented in Figure 6 and Table 3. As shown in Figure 6, it was clearly observed that the bending strength and toughness increased as the PA fiber content increased. Also, the second peak tended to increase as the PA fiber content increased.

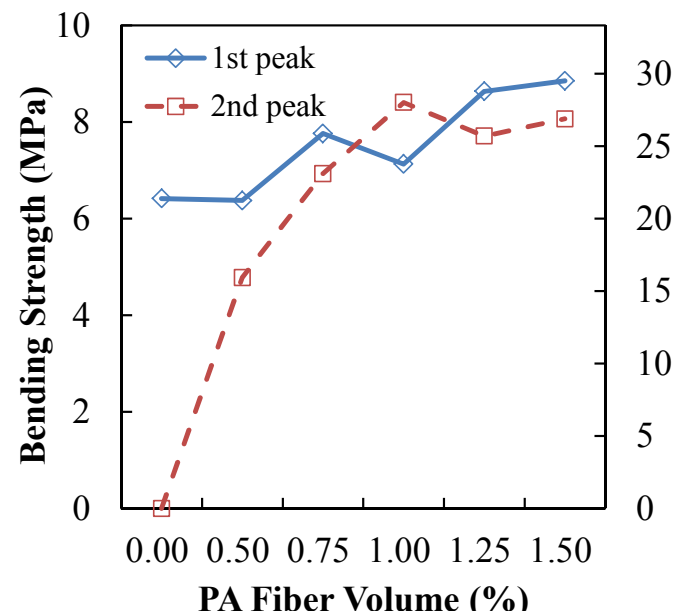

(a)

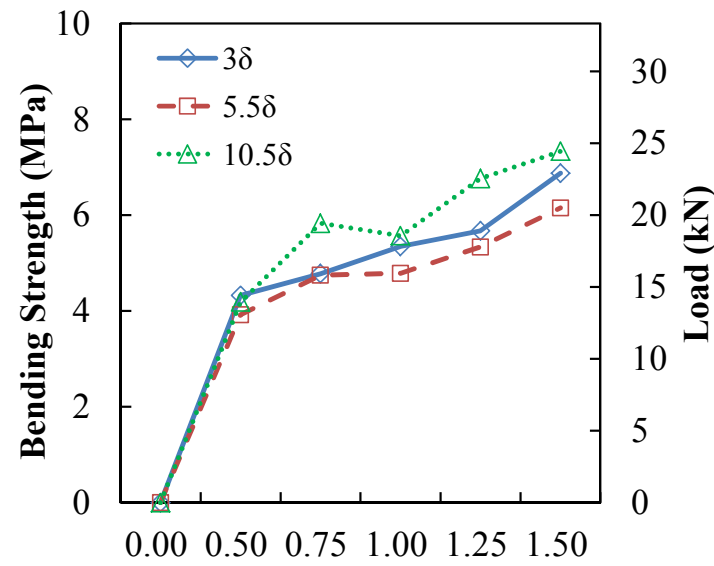

PA Fiber Volume (\%)

(c)

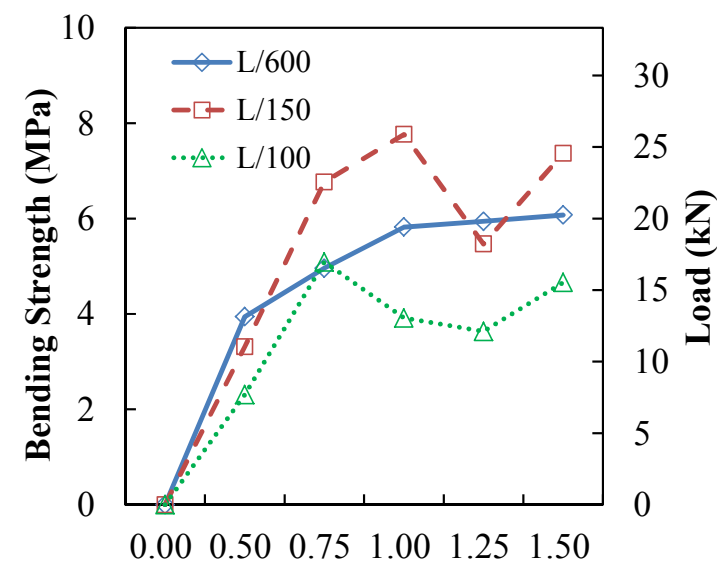

PA Fiber Volume (\%)

(e)

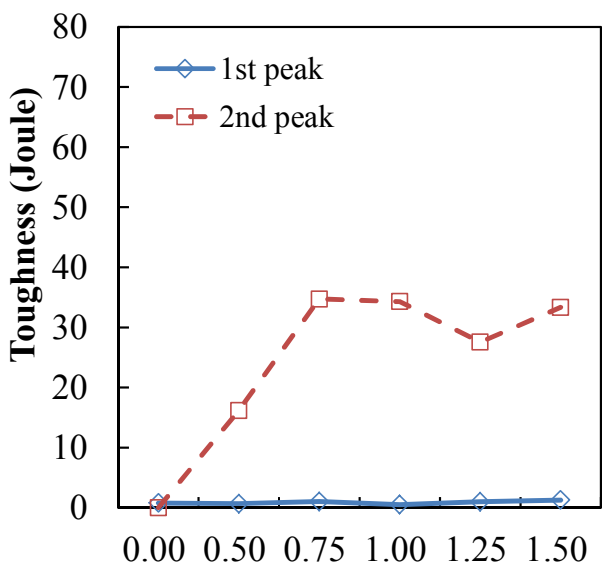

PA Fiber Volume (\%)

(b)

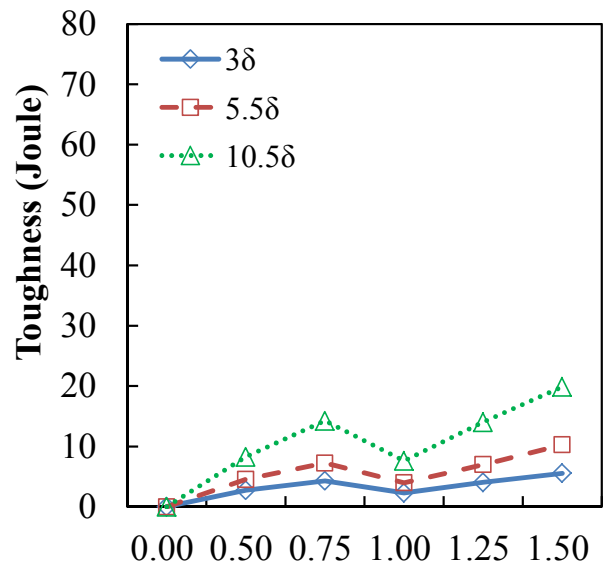

PA Fiber Volume (\%)

(d)

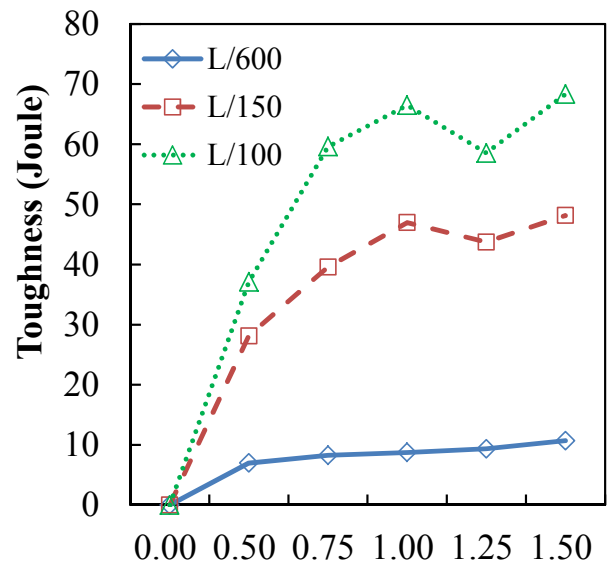

PA Fiber Volume (\%)

(f)

Figure 6. Figure 6. (a) Bending strength (first and second peaks); (b) toughness (first and second peaks); (c) bending strength $(3 \delta, 5.5 \delta, 10.5 \delta)$; (d) toughness $(3 \delta, 5.5 \delta, 10.5 \delta)$; (e) bending strength (L/600, L/150, L/100); (f) toughness (L/600, L/150, L/100). 
Table 3. Average value of flexural responses of PAFRS.

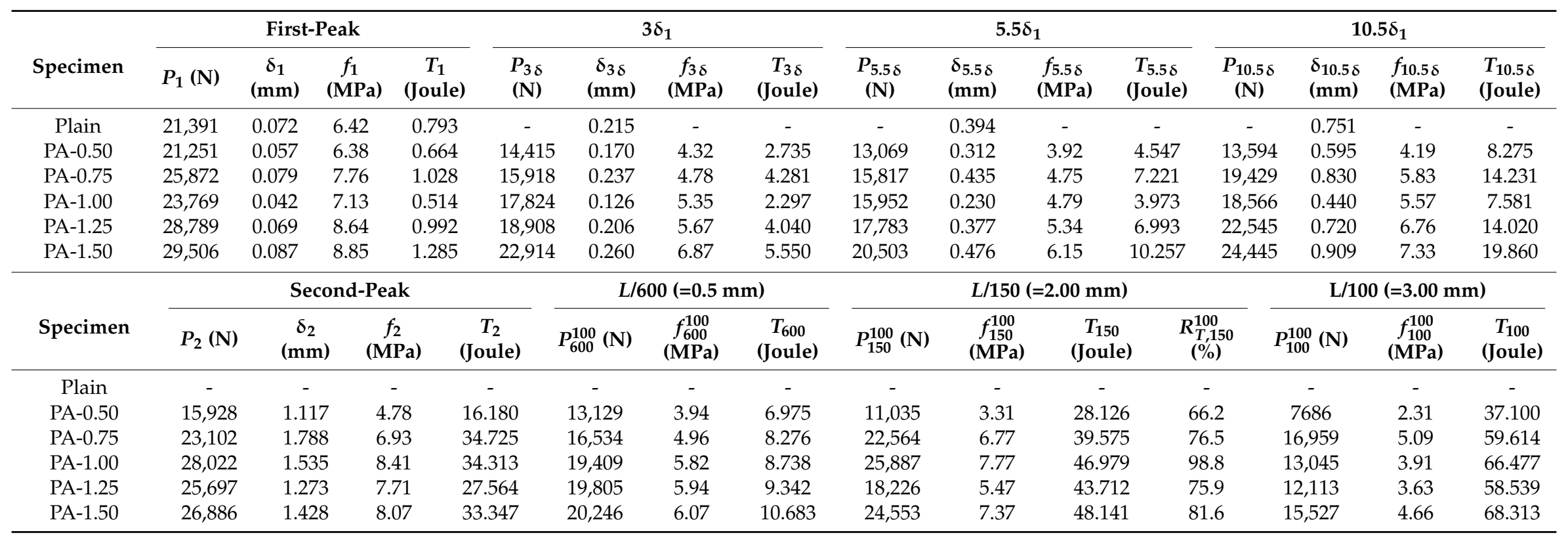




\section{Field and Laboratory Fabricated PAFRS}

For tunnel application of PAFRS, field and laboratory specimens were fabricated according to the approach discussed earlier, and the flexural performance was evaluated in accordance with ASTM C1609/C1609M-12 [21] and the Morgan level [14]. First, appropriate PA fiber content was determined based on the bending strength in Equation (1) and equivalent bending strength in Equation (2), since compressive strengths of PAFRS in Figure 3 were far higher than the minimum limit in Table 4. There are four applicable Korean tunnel design guidelines for fiber-reinforced shotcrete, listed in Table 4. All four design guidelines specify the minimum compressive strength, bending strength, and equivalent bending strength. For this study, $0.6 \% \sim 0.8 \%$ of PA fiber content was determined to be the optimal content based on Table 3, and both laboratory and field specimens were then prepared. Shotcrete mix design such as the maximum gravel size $\left(\mathrm{G}_{\max }\right)$, ratio of water to cement $(\mathrm{W} / \mathrm{C})$ and sand to aggregate (S/a), unit weight of water (W), cement (C), crushed sand (CS), gravel (G), polyamide fiber (PA). and water-reducing admixture (AD) is presented in Table 5 . The test specimens were fabricated from tunnel lining shotcrete during construction as in Figure 7a and dimensions of specimens and the test setup were slightly modified to meet the Korean standard and are presented in Figure $7 \mathrm{~b}$. For each shotcrete mix design, three specimens were prepared and tested.

Table 4. Korean design guidelines for tunnel shotcrete.

\begin{tabular}{|c|c|c|c|c|c|}
\hline Property & Unit & $\begin{array}{c}\text { Korean Highway } \\
\text { Design Specifications } \\
\text { (2012) [24] }\end{array}$ & $\begin{array}{c}\text { Korean Railroad } \\
\text { Design Specifications } \\
\text { (2011) [25] }\end{array}$ & $\begin{array}{c}\text { Korean High Speed } \\
\text { Railroad Design } \\
\text { Specifications (2005) } \\
{[26]}\end{array}$ & $\begin{array}{c}\text { Korean Tunnel } \\
\text { Design Specifications } \\
\text { (2007) [27] }\end{array}$ \\
\hline Bending Strength & $\mathrm{MPa}$ & $>4.4$ (28 days) & $>4.5$ ( 28 days) & $>4.5$ ( 28 days $)$ & $>4.5$ ( 28 days) \\
\hline
\end{tabular}

Table 5. Shotcrete mix design.

\begin{tabular}{|c|c|c|c|c|c|c|c|c|c|c|}
\hline \multirow{2}{*}{ Specimen } & \multirow{2}{*}{$\mathrm{G}_{\max }(\mathrm{mm})$} & \multirow{2}{*}{ W/C (\%) } & \multirow{2}{*}{ S/a (\%) } & \multicolumn{6}{|c|}{ Unit Weight $\left(\mathrm{kg} / \mathrm{m}^{3}\right)$} & \multirow{2}{*}{$\underset{\left(B^{* * *} \%\right)}{\operatorname{AD}}$} \\
\hline & & & & $\mathbf{W}$ & $\mathrm{C}$ & $S$ & $\mathrm{CS}$ & G & PA & \\
\hline PA-0.6L * & 10 & 43.5 & 60 & 211 & 485 & 472 & 463 & 617 & 6.84 & 0.9 \\
\hline PA- $0.6 \mathrm{~F} * *$ & 10 & 43.5 & 60 & 211 & 485 & 472 & 463 & 617 & 6.84 & 1.0 \\
\hline PA-0.7L & 10 & 43.5 & 60 & 211 & 485 & 472 & 463 & 617 & 7.98 & 1.0 \\
\hline PA-0.7F & 10 & 43.5 & 60 & 211 & 485 & 472 & 463 & 617 & 7.98 & 1.1 \\
\hline PA-0.8L & 10 & 43.8 & 60 & 211 & 482 & 385 & 578 & 651 & 9.12 & 1.1 \\
\hline PA-0.8F & 10 & 43.8 & 60 & 211 & 482 & 385 & 578 & 651 & 9.12 & 1.2 \\
\hline
\end{tabular}

* PA-xxL: mixed in laboratory; ** PA-xxF: mixed in field; ${ }^{* * *}$ weight percentage to binder.

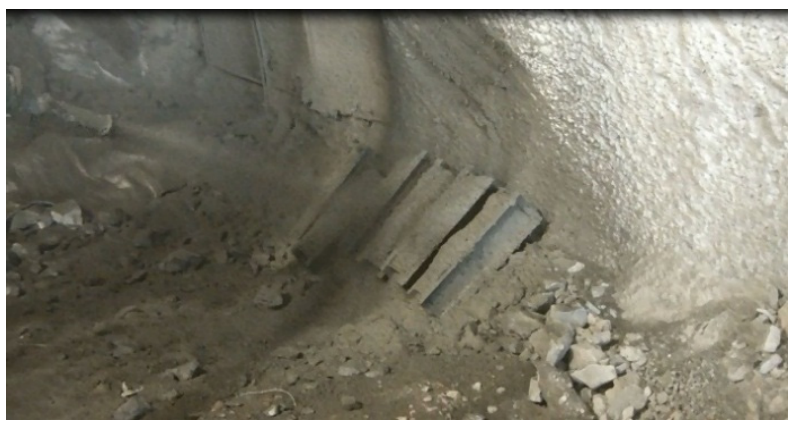

(a)

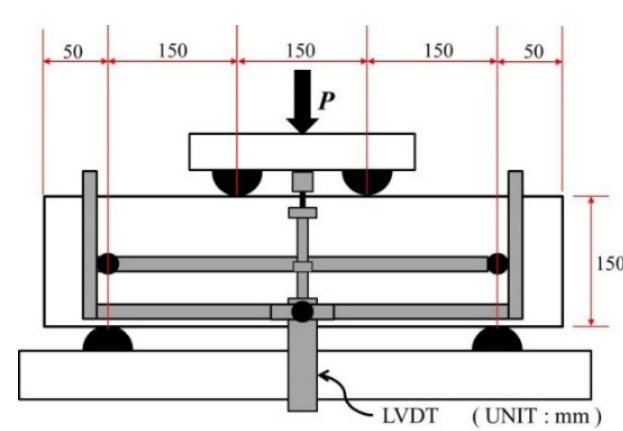

(b)

Figure 7. (a) Shotcrete specimen fabrication; (b) specimen geometry and test setup. 
Bending and equivalent bending strength test results from the laboratory and field are presented in Table 6. All PAFRS specimens fabricated in both laboratory and field exhibited higher bending and equivalent bending strengths (see Table 7) than the minimum limits in Table 4. Load-deflection relationship of all specimens was also investigated, as in Figure 8. The load-deflection curves of PAFRS specimens were similar to each other due to the small variation of PA fiber content. Detailed PAFRS bending strength and toughness with respect to varying fiber content are presented in Figure 9. The average flexural responses at $\delta_{1}, 3 \delta_{1}, 5.5 \delta_{1}, L / 600,10.5 \delta_{1}$, and L/150 are summarized in Table 7 . As shown in the results, the quality and performance of field specimens were similar to those of laboratory specimens.

Table 6. Bending and equivalent bending strength.

\begin{tabular}{ccccccccc}
\hline \multirow{2}{*}{ Specimen } & \multicolumn{3}{c}{ Bending Strength (MPa) } & \multicolumn{3}{c}{ Equivalent Bending Strength (MPa) } \\
\cline { 2 - 9 } & SP-1 & SP-2 & SP-3 & Avg. & SP-1 & SP-2 & SP-3 & Avg. \\
\hline PA-0.6L & 6.01 & 6.25 & 5.70 & 5.99 & 3.63 & 3.72 & 3.38 & 3.57 \\
PA-0.6F & 6.18 & 5.97 & 5.78 & 5.98 & 3.33 & 3.59 & 3.46 & 3.46 \\
PA-0.7L & 6.02 & 6.48 & 5.89 & 6.13 & 3.60 & 3.32 & 3.93 & 3.62 \\
PA-0.7F & 5.39 & 4.97 & 5.13 & 5.16 & 3.83 & 3.32 & 3.67 & 3.61 \\
PA-0.8L & 6.16 & 5.98 & 6.13 & 6.09 & 3.41 & 3.58 & 3.74 & 3.57 \\
PA-0.8F & 5.49 & 5.50 & 5.65 & 5.55 & 3.63 & 3.42 & 3.76 & 3.60 \\
\hline \multicolumn{9}{c}{ PA-xxL: mixed in laboratory; PA-xxF: mixed in field. }
\end{tabular}

PA-xxL: mixed in laboratory; PA-xxF: mixed in field.

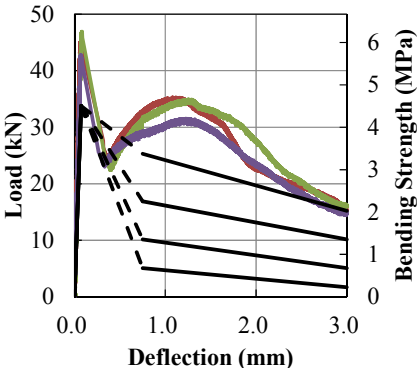

(a)

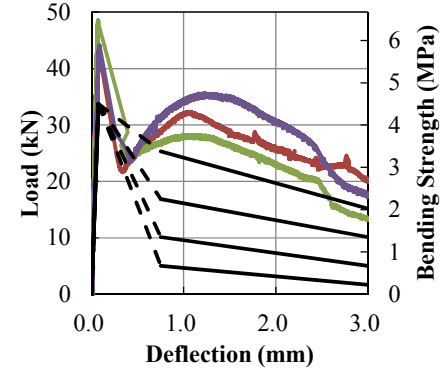

(c)

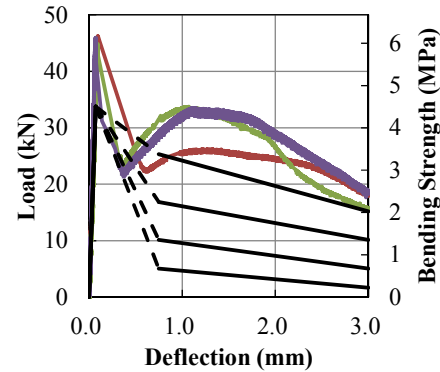

(e)

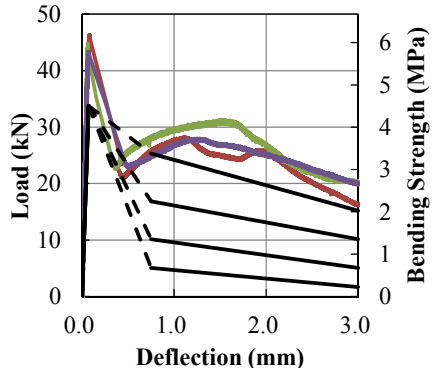

(b)

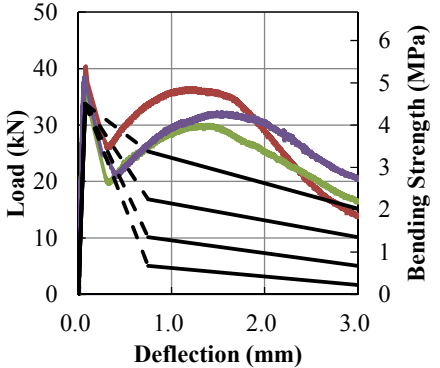

(d)

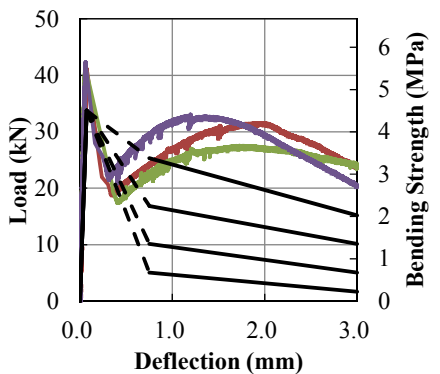

(f)

Figure 8. (a) PA-0.6L; (b) PA-0.6F; (c) PA-0.7L; (d) PA-0.7F; (e) PA-0.8L; (f) PA-0.8F. 
Table 7. Average value of flexural responses of PAFRS.

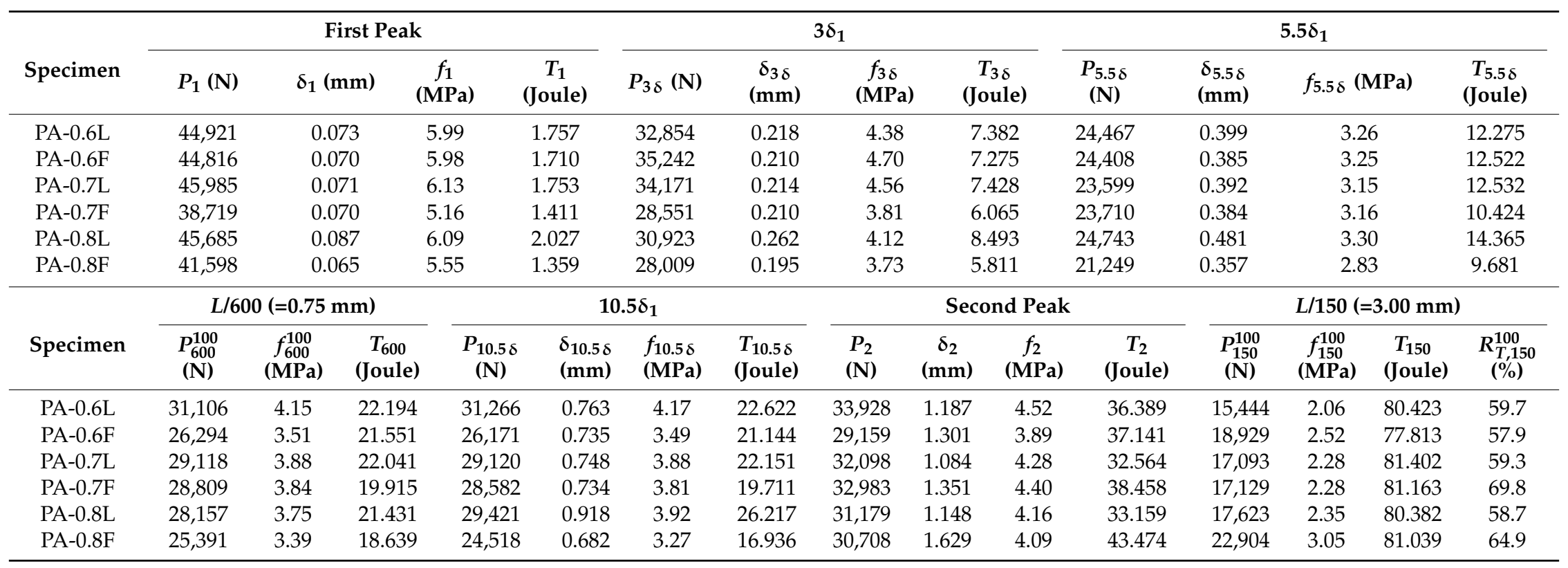




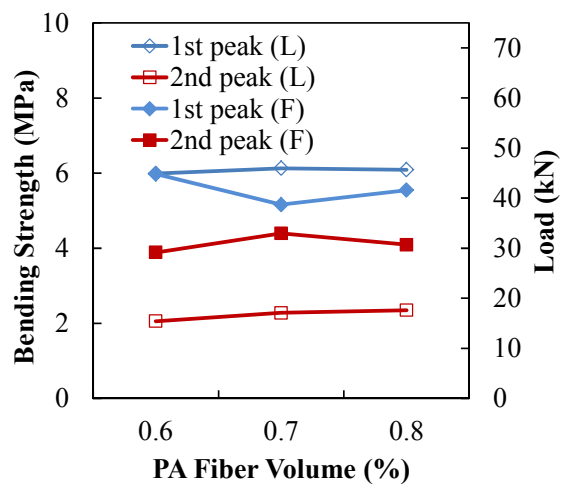

(a)

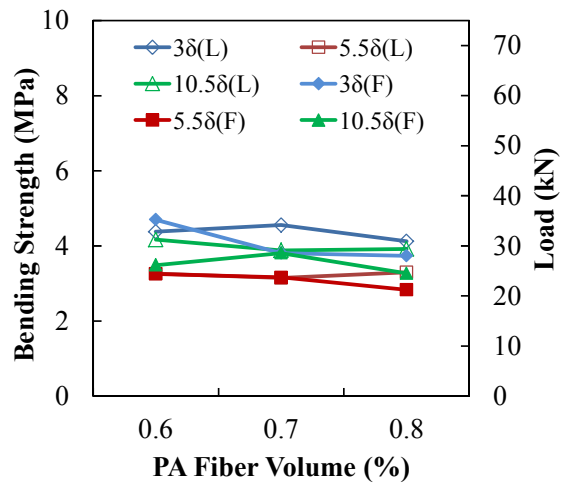

(c)

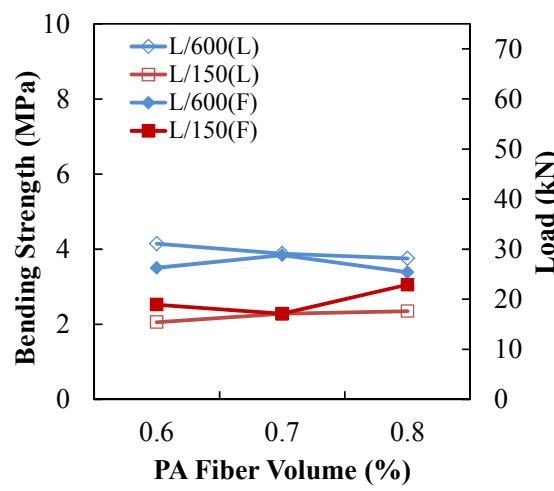

(e)

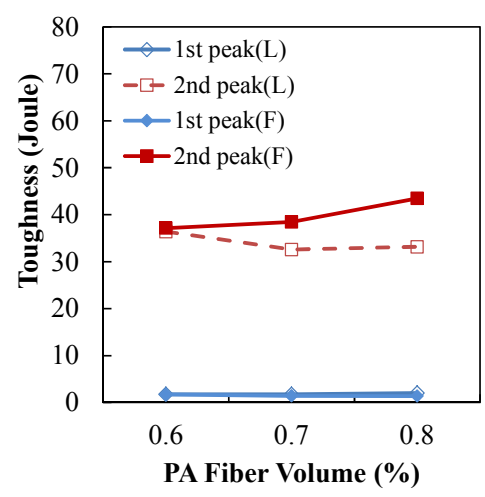

(b)

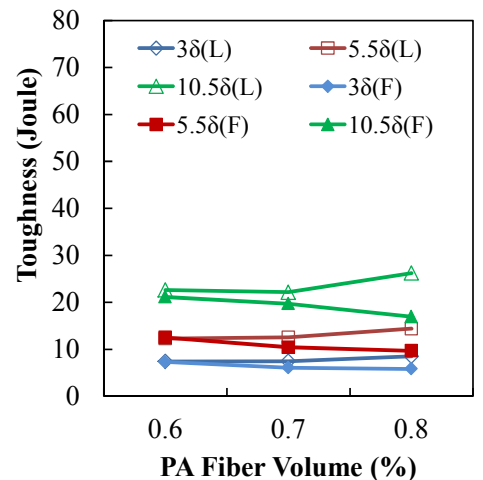

(d)

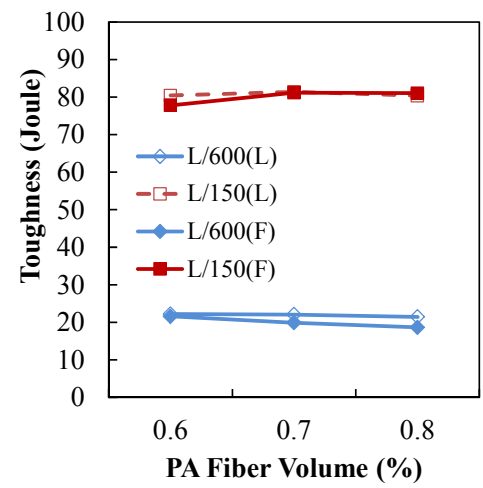

(f)

Figure 9. (a) Bending strength (first and second peaks); (b) toughness (first and second peaks); (c) bending strength $(3 \delta, 5.5 \delta, 10.5 \delta)$; (d) toughness $(3 \delta, 5.5 \delta, 10.5 \delta)$; (e) bending strength $(\mathrm{L} / 600, \mathrm{~L} / 150)$; (f) toughness (L/600, L/150).

Based on the load-deflection curves in Figure 8, Morgan levels [14] for each specimens were determined to identify the toughness performance level, as presented in Table 8 . The Morgan level evaluates the strength of steel fiber reinforced shotcrete at $\delta_{1} L / 600$ and $L / 150$. However, PAFRSs exhibit different load-deflection history compared to SFRCs, although the Morgan level was originally suggested for SFRCs. After the first peak in Figure 8, the load-deflection curve drops until the PA fiber takes the load, then starts to increase up to the second peak or ultimate fiber capacity. Figure 9a shows that the second peaks of all specimens were larger than or equal to the first peak. As shown in Figure 8, some of the load-deflection curves of PAFRS specimens at $L / 600$ after the first peak dropped below the Morgan level IV. However, the load-deflection curves increase again, beyond level IV. Thus, this study evaluated the specimen capacity in terms of toughness. The toughness of each specimen was compared to the toughness specified by Morgan load-deflection curves. The toughness Morgan 
levels [14] of all specimens were Level IV while the strength Morgan levels of all specimens were Level III.

Table 8. Morgan level based on strength and toughness.

\begin{tabular}{cccccccc}
\hline Method Basis & Specimen No. & PA-0.6L & PA-0.6F & PA-0.7L & PA-0.7F & PA-0.8L & PA-0.8F \\
\hline \multirow{4}{*}{ Strength } & 1 & IV & IV & IV & III & III & III \\
& 2 & IV & IV & III & IV & IV & III \\
& Min. Level & III & III & IV & IV & IV & IV \\
& 1 & IV & IV & IV & IV & IV & IV \\
Toughness & 2 & IV & IV & IV & IV & IV & IV \\
& 3 & IV & IV & IV & IV & IV & IV \\
& Min. Level & IV & IV & IV & IV & IV & IV \\
\hline
\end{tabular}

\section{PAFRS Shotcrete Application Results}

The PAFRS of PA-0.7F in Tables 5-7 was conservatively selected and was used in tunnel shotcrete to evaluate shotcrete stresses and rebounding rate for constructability, as presented in Figure 10. For comparison, steel fiber ( $0.5 \mathrm{~mm}$ diameter, $30 \mathrm{~mm}$ long and hooked type) reinforced shotcrete was also applied at the same construction site. Also, four sample cores with an average thickness of $168 \mathrm{~mm}$ were collected to confirm the shotcrete thickness and contact to the rock. The flexural strength of the specimen was satisfactory compared to the tunnel codes, as presented in Table 7.

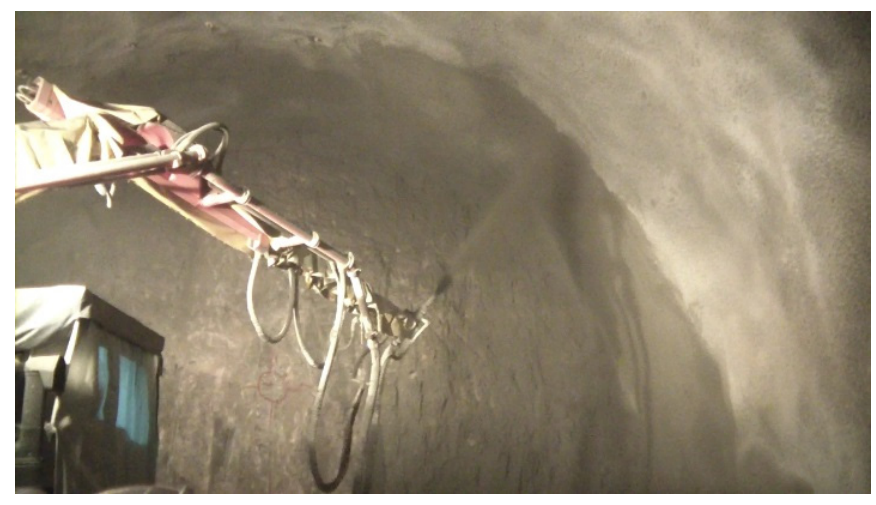

Figure 10. Shotcrete spouting and rebounding test.

Also, the flexural stress limits by Korean Tunnel Design Specifications [27] were checked. The measured shotcrete stresses are presented in Table 9. Both PA and steel fiber reinforced shotcrete satisfied the allowable limits (allowable flexural compressive stress $=8.4 \mathrm{MPa}$, allowable flexural tensile stress $=0.60 \mathrm{MPa}$ ). The maximum compressive and tensile stresses of PA shotcrete were observed at the crown and the East springline, respectively, but the stress was only $2.5 \%$ and $10 \%$ with respect to the allowable stresses.

Table 9. Measured shotcrete stresses.

\begin{tabular}{|c|c|c|c|c|c|c|}
\hline $\begin{array}{c}\text { Location } \\
\text { Fiber }\end{array}$ & \multicolumn{2}{|c|}{ Springline (East) } & \multicolumn{2}{|c|}{ Springline (West) } & \multicolumn{2}{|c|}{ Crown } \\
\hline PA & - & 0.06 & 0.19 & 0.06 & 0.21 & 0.05 \\
\hline Steel & - & 0.37 & 0.01 & 0.23 & 0.36 & 0.27 \\
\hline
\end{tabular}


Finally, PA shotcrete rebounding was checked to identify the fiber ratio included and dropped in the final shotcrete. The test procedure is presented in Figure 11. The rebounding test results are presented in Table 10. The average rebounding rate was $8.5 \%$, which is less than the limit of $12.5 \%$ designated by Korean Tunnel Design Specifications [27]. The average dropped fiber rate was $63.5 \%$. The average fiber content rate was $103.4 \%$.

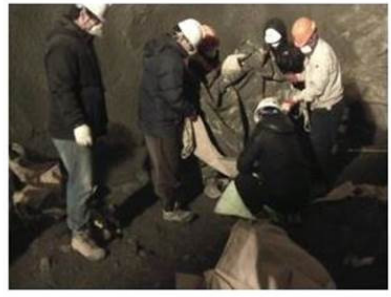

Collect rebounds

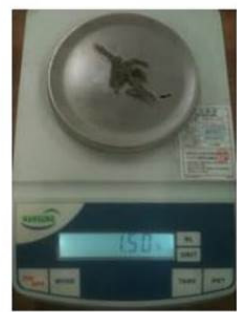

Weighing PA fibers

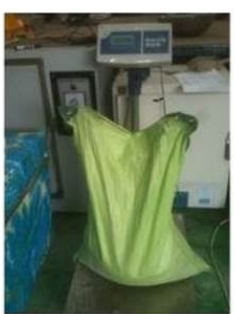

Weighing

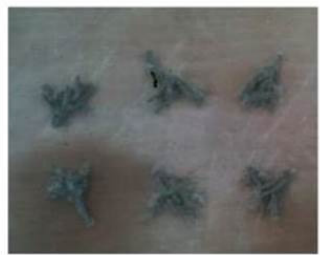

PA fibers

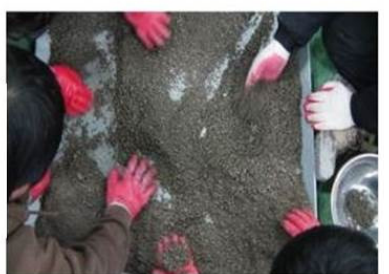

Collect sample

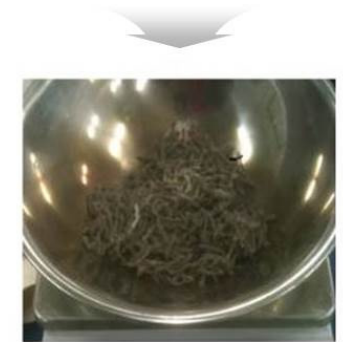

Fiber sample

Figure 11. PA shotcrete rebounding test procedure.

Table 10. PAFRS rebounding test results.

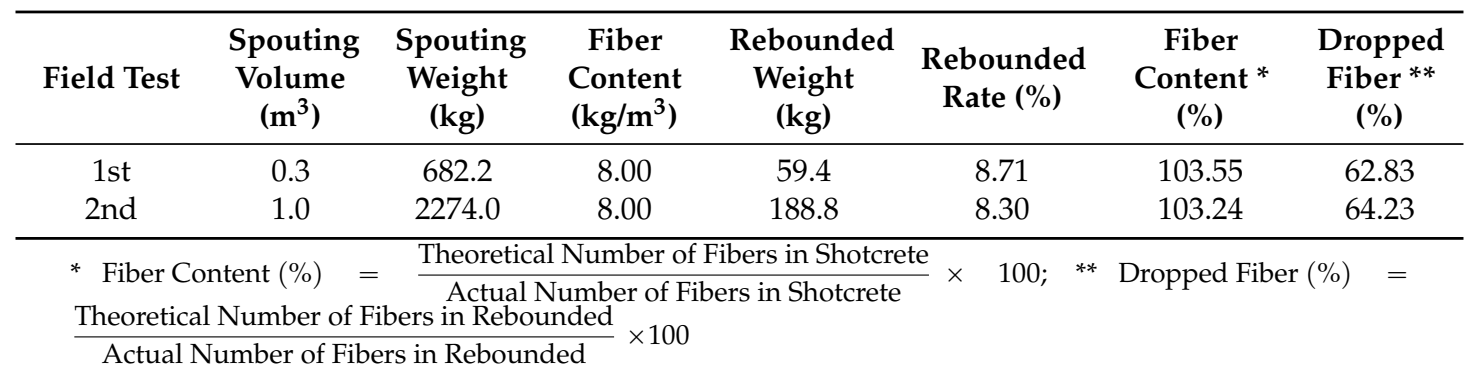

\section{Conclusions}

This study performed laboratory tests to investigate the influence of PA fiber content and to determine the appropriate PA fiber content for tunnel shotcrete application. As expected, PAFRS flexural performance improved as PA fiber contents increased from $0.5 \%$ to $1.5 \%$. Since the experimental results of all specimens exhibited far higher flexural performance than the required levels, $0.6 \sim 0.8 \%$ of PA fiber content was selected for a field application. In this study, three PAFRS specimens for each PA fiber content were prepared in the laboratory and field to compare the flexural performance and toughness. Finally, PA- 0.7 was selected and used in tunnel shotcrete. In the field, steel fiber reinforced shotcrete was also used for comparison. Both PA and steel fiber reinforced shotcrete satisfied the allowable stress limits by Korean Tunnel Design Specifications [27]. Also, fiber rebounding tests exhibited the constructability and quality of PA shotcrete, based on its low rebounding rate $(8.5 \%)$ and low fiber drop (63.5\%). Based on these results, the fiber content in the shotcrete was expected to be $103.4 \%$ Therefore, PA shotcrete applied in a tunnel exhibited stability and constructability. 
Acknowledgments: This research was supported by a grant from the Construction Technology Research Project (Development of impact/blast resistant HPFRCC (High Performance Fiber Reinforced Cementitious Composites) and evaluation technique thereof (13SCIPS02)) funded by the Ministry of Land, Infrastructure, and Transport and research fund of Chungnam National University.

Author Contributions: Joong Kyu Jeon planned and performed the laboratory and field experimental tests. WooSeok Kim analyzed the experiments, drafted the manuscript, and revised it. Gyu Yong Kim performed laboratory tests. Chan Ki Jeon guided this study and provided valuable comments.

Conflicts of Interest: The authors declare no conflict of interest.

\section{References}

1. Kim, D.J.; Kang, S.H.; Ahn, T. Mechanical characterization of high-performance steel-fiber reinforced cement composites with self-healing effect. Materials 2014, 7, 508-526. [CrossRef]

2. Kim, D.J.; Park, S.H.; Ryu, G.S.; Koh, K.T. Comparative flexural behavior of hybrid ultra high performance fiber reinforced concrete with different macro fibers. Constr. Build. Mater. 2011, 25, 4144-4155. [CrossRef]

3. Mindess, S.; Chen, L.; Morgan, D.R. Determination of the first-crack strength and flexural toughness of steel fiber-reinforced concrete. Adv. Cem. Based. Mater. 1994, 1, 201-208. [CrossRef]

4. Soroushian, P.; Elyamany, H.; Tlili, A.; Ostowari, K. Mixed-mode fracture properties of concrete reinforced with low volume fractions of steel and polypropylene fibers. Cem. Concr. Compos. 1998, 20, 67-78. [CrossRef]

5. Song, P.S.; Hwang, S.; Sheu, B.C. Strength properties of nylon- and polypropylene-fiber-reinforced concretes. Cem. Concr. Res. 2005, 35, 1546-1550. [CrossRef]

6. Bencardino, F.; Rizzuti, L.; Spadea, G.; Swamy, R.N. Experimental evaluation of fiber reinforced concrete fracture properties. Compos. B Eng. 2010, 41, 17-24. [CrossRef]

7. Alberti, M.G.; Enfedaque, A.; Gavez, J.C. On the mechanical properties and fracture behavior of polyolefin fiber-reinforced self-compacting concrete. Constr. Build. Mater. 2014, 55, 274-288. [CrossRef]

8. Yap, S.P.; Alengaram, U.J.; Jumaat, M.Z. Enhancement of mechanical properties in polypropylene- and nylon-fibre reinforced oil palm shell concrete. Mater. Des. 2013, 49, 1034-1041. [CrossRef]

9. Zhu, J.; Zhu, M.; Han, N.; Liu, W.; Xing, F. Electrical and mechanical performance of carbon fiber-reinforced polymer used as the impressed current anode material. Materials 2014, 7, 5438-5453. [CrossRef]

10. Nishiwaki, T.; Kwon, S.; Homma, D.; Yamada, M.; Mihashi, H. Self-healing capability of fiber-reinforced cementitious composites for recovery of watertightness and mechanical properties. Materials 2014, 7, 2141-2154. [CrossRef]

11. Bencardino, F.; Rizzuti, L.; Spadea, G.; Swamy, R.N. Implications of test methodology on postcracking and fracture behaviour of steel fibre reinforced concrete. Compos. B Eng. 2013, 46, 31-38. [CrossRef]

12. Kant, M.; Penumadu, D. Dynamic mechanical characterization for nonlinear behavior of single carbon fibers. Compos. A 2014, 66, 201-208. [CrossRef]

13. Franzen, T. Shotcrete for underground support; a state-of-the-art report with focus on steel-fibre reinforcement. Tunn. Undergr. Space Technol. 1992, 7, 383-391. [CrossRef]

14. Morgan, D.R.; Chen, L.; Beaupre, D. Toughness of fibre reinforced shotcrete. In Proceedings of the Shotcrete For Underground Support VII, Buchen-Telfs, Telfs-Buchen, Austria, 11-15 June 1995; pp. 66-87.

15. Jeng, F.; Lin, M.-L.; Yuan, S.-C. Performance of toughness indices for steel fiber reinforced shotcrete. Tunn. Undergr. Space Technol. 2002, 17, 69-82. [CrossRef]

16. Cengiz, O.; Turanli, L. Comparative evaluation of steel mesh, steel fibre and high performance polypropylene fibre reinforced shotcrete in panel test. Cem. Concr. Res. 2004, 34, 1357-1364. [CrossRef]

17. Yoon, J.H.; Jeon, J.K.; Kim, Y.K.; Chung, J.M. A feasibility study on polyamide fiber reinforced shotcrete for rock support in a tunnel. In Proceedings of the World Tunnel Congress 2013, Geneva, Switzerland, 31 May-5 June 2013; pp. 1-8.

18. Jeon, J.K.; Kim, W.; Jeon, C.K.; Kim, J.C. Processing and mechanical properties of macro polyamide fiber reinforced concrete. Materials 2015, 7, 7634-7652. [CrossRef]

19. Elasto Plastic Concrete. Available online: http:/ / www.elastoplastic.com (accessed on 8 January 2014).

20. Choi, E.; Kim, D.; Chung, Y.; Nam, T. Bond-slip characteristics of SMA reinforcing fibers obtained by pull-out test. Mater. Res. Bull. 2014, 58, 28-31. [CrossRef] 
21. Structural Test Method for Flexural Performance of Fiber Reinforced Concrete (Using Beam with Third Point Loading); ASTM C 1609/C1609M-12; American Society of Testing and Materials: West Conshohocken, PA, USA, 2006; pp. 1-8.

22. Structural Test Method for Flexural Toughness and First Crack Strength of Fiber Reinforced Concrete (Using Beam with Third Point Loading); ASTM C1018-97; American Society of Testing and Materials: West Conshohocken, PA, USA, 1998; pp. 514-515.

23. RILEM TCS. Determination of the fracture energy of mortar and concrete by means of three-point bend tests on notched beams. Mater. Struct. 1985, 18, 285-290.

24. Tunnel; Korean Highway Design Specifications. Ministry of Land, Infrastructure and Transport: Sejoing, Korea, 2012.

25. Tunnel; Korean Railroad Design Specifications. Korea Rail Network Authority: Daejeon, Korea, 2011.

26. Tunnel; Korean High Speed Railroad Design Specifications. Korea Rail Network Authority: Daejeon, Korea, 2005.

27. Shotcrete; Korean Tunnel Design Specifications. Ministry of Land, Infrastructure and Transport: Sejoing, Korea, 2007.

(C) 2016 by the authors; licensee MDPI, Basel, Switzerland. This article is an open access article distributed under the terms and conditions of the Creative Commons by Attribution (CC-BY) license (http://creativecommons.org/licenses/by/4.0/). 